\title{
ANALISIS KETERSEDIAAN DAYA DAN KEANDALAN SISTEM JARINGAN DISTRIBUSI DI UNIVERSITAS BORNEO TARAKAN
}

\author{
Patria Julianto $^{1}$, Julidar Sidebang ${ }^{2}$ \\ ${ }^{1,2}$ Universitas Borneo Tarakan, Tarakan, Kalimantan Utara, Indonesia \\ 1patria81@gmail.com \\ 2julidar21sidebang@gmail.com
}

\begin{abstract}
Reliability level is one of the vital things in the distribution of electricity. A reliable distribution system will ensure a continuous level of service in the distribution system. In this channeling system, care should be taken regarding the use of the carrier type, the distribution system, or the protection or protection of the channeling. The purpose of this research is to calculate the existing power in the low voltage distribution network system at the University of Borneo Tarakan, and the method used is descriptive method. The results showed that the low voltage distribution network system at the University of Borneo Tarakan there are some deviations in the loading of unbalanced loads on each building, air and ground wire and ground meets the standards. The availability of power and reliability of distribution network system at Tarakan Borneo University is calculated as 0.92409 and 0.99981 . For reliability index of whole distribution system based on SAIFI calculation: 0.2 f / yr, SAIDI: $3 \mathrm{~h} / \mathrm{yr}$, CAIDI: $15 \mathrm{~h} / \mathrm{yr}$, ASAI: $0.9996 \mathrm{pu}$, ASUI: $0.00034 \mathrm{pu}$. This can be interpreted that the availability of power and reliability of the distribution network at the University of Borneo Tarakan reliably.
\end{abstract}

Keywords - Reliability, distribution system, low voltage, University of Borneo Tarakan.

Intisari-Tingkat keandalan merupakan salah satu hal yang vital dalam penyaluran tenaga listrik. Sistem distribusi yang andal akan menjamin tingkat kontinuitas pelayanan pada sistem distribusi. Dalam sistem penyaluran ini harus diperhatikan mengenai penggunaan jenis penghantar, sistem penyalurannya, maupun proteksi atau pengaman dari penyaluran. Tujuan dari penelitian ini adalah untuk menghitung daya yang ada pada sistem jaringan distribusi tegangan rendah di Universitas Borneo Tarakan, dan metode yang digunakan adalah metode deskriptif. Hasil penelitian menunjukkan bahwa sistem jaringan distribusi tegangan rendah di Universitas Borneo Tarakan ada beberapa penyimpangan dalam pembebanan yaitu tidak seimbangnya beban pada tiap gedung, kawat penghantar udara dan tanah sudah memenuhi standar. Ketersediaan daya dan keandalan sistem jaringan distribusi di Universitas Borneo Tarakan terhitung sebesar 0,92409 dan 0,99981. Untuk indeks keandalan sistem distribusi keseluruhan berdasarkan perhitungan SAIFI: 0,2 f/yr, SAIDI: $3 \mathrm{~h} / \mathrm{yr}$, CAIDI: $15 \mathrm{~h} / \mathrm{yr}$, ASAI: 0,9996 pu, ASUI: 0,00034 pu. Hal ini dapat diartikan bahwa ketersediaan daya dan keandalan jaringan distribusi di Universitas Borneo Tarakan andal.

Kata Kunci-Keandalan, sistem distribusi, tegangan rendah, Universitas Borneo Tarakan.

\section{PENDAHULUAN}

Seiring dengan meningkatnya kemajuan teknologi, peralatan pada jaringan distribusi mengalami modernisasi dan otomatisasi, hal ini dimaksudkan untuk meningkatkan keandalan dalam proses penyaluran tenaga listrik. Penyaluran tenaga listrik merupakan suatu hal yang penting, karena energi listrik yang dibangkitkan harus disalurkan melalui saluran transmisi atau distribusi[1]. Saluran ini membawa tenaga listrik dari pusat tenaga listrik melalui saluran tenaga listrik melalui saluran penghubung, gardu-gardu induk (substations) dan gardu distribusi, dengan tegangan $150 \mathrm{kV}, 70 \mathrm{kV}, 20 \mathrm{kV}$, sampai tegangan untuk konsumen, yaitu 380/220 Volt, kenaikan dan penurunan tegangan ini dilakukan dengan transformator[2]. Universitas Borneo Tarakan sebagai salah satu konsumen PT. PLN Tarakan menggunakan energi listrik yang cukup besar, mengingat UBT adalah institusi pendidikan yang membutuhkan listrik sebagai pendukung utama dalam hal peyelenggara pendidikan tinggi, sehingga memerlukan suplai energi listrik yang andal.Untuk menentukan atau menghitung tegangan, arus, daya, dan faktor daya atau daya reaktif yang terdapat pada berbagai titik dalam suatu jaringan listrik pada keadaan pengoperasian normal, baik yang sedang berjalan maupun yang diharapkan akan terjadi di masa yang akan datang.Sebagai solusi dari permasalahan tersebut, Dilakukan penelitian dengan judul "Analisis Ketersediaan Daya dan Keandalan Sistem Jaringan Distribusi di Universitas Borneo Tarakan".Adapun tujuan penelitian ini adalah untuk menghitung daya yang ada pada sistem jaringan distribusi tegangan rendah di Universitas Borneo Tarakan.

\section{METODE PENELITIAN}

\section{A. Tempat dan Waktu Penelitian}

Metode yang digunakan untuk penelitian ini adalah penelitian deskriptif. Metode penelitian deskriptif sebagai kegiatan yang meliputi pengumpulan data dalam rangka menguji hipotesis atau menjawab pertanyaan yang menyangkut keadaan yang sedang berjalan dari pokok suatu penelitian. Penelitian tentang sistem jaringan distribusi di Universitas Borneo Tarakan ini akan dilaksanakan selama tiga bulan pada bulan Maret hingga bulan Juni 2017. Sedangkan lokasi yang digunakan dalam penelitian ini adalah jaringan distribusi yang ada di gedung rektorat baru, gedung rektorat lama, gedung Fakultas Hukum, gedung Fakultas Ekonomi, gedung Fakultas Keguruan dan Ilmu Pendidikan, gedung Fakultas Teknik, gedung Fakultas Perikanan dan Ilmu Kelautan, dan gedung Fakultas Pertanian. 


\section{B. Metode Penelitian}

Metode yang digunakan dalam penyeselesaian penelitian analisis ketersediaan daya dan keandalan sistem jaringan distribusi di Universitas Borneo Tarakan menggunakan beberapa metode, yaitu:

1. Metode literatur

Metode pengambilan data dengan cara membaca dan mempelajari buku-buku yang berkaitan dengan penelitian

2. Metode Wawancara

Yaitu konsultasi dengan dosen pembimbing skripsi, serta orang-orang lapangan yang dianggap memiliki pengetahuan dan wawasan terhadap permasalahan yang dibahas padapenelitian ini.

3. Observasi

Pengambilan data melakukan pengkuran secara langsung dilapangan bersama pendamping teknisi di Universitas Borneo Tarakan.

\section{HASIL DAN PEMBAHASAN}

Berdasarkan deskripsi data dari hasil penelitian mengenai sistem jaringan distribusi di Universitas Borneo Tarakan mempunyai 2 transformator distribusi, dapat dianalisis sebagai berikut:

\section{A. Transformator Distribusi 200 KVA}

Transformator distribusi yang telah terpasang di Universitas Borneo Tarakan merupakan transformator penurun tegangan dari tegangan distribusi 20.000 Volt menjadi 400 Volt dan penggunaannya adalah satu transformator untuk menyuplai khusus gedung E1 (Rektorat Baru).

\section{B. Transformator Distribusi 1250 KVA}

Gardu beton transformator distribusi merupakan transformator penurun tegangan dari distribusi 20.000 Volt menjadi 400 Volt penggunaannya adalah sejumlah pemakai untuk gedung-gedung perkuliahan, ruang dekan maupun laboratorium-laboratorium yang ada di Universitas Borneo Tarakan. Satu transformator ini menyuplai 9 titik beban gedung yang ada di Universitas Borneo Tarakan yaitu:

1. Gedung E2 (Rektorat Lama)

2. Gedung E3 (Fakultas Hukum, Ruang Dekan)

3. Gedung E4 (Fakultas Ekonomi, Ruang Dekan)

4. Gedung E5 (Fakultas Keguruan dan Ilmu Pendidikan, Ruang Dekan)

5. Gedung E6 (Fakultas Teknik, Ruang Dekan)

6. Gedung E7 (Fakultas Perikanan dan Ilmu Kelautan, Ruang Dekan)

7. Gedung E8 (Fakultas Pertanian, Ruang Dekan)

8. Gedung E9 (LAB Fakultas Teknik Sipil)

9. Gedung E10 (Rusunawa)

\section{Sistem Jaringan Distribusi}

Sistem jaringan yang digunakan adalah sistem jaringan radial dimana bentuk jaringannya terlihat sederhana, aliran jaringan hanya berasal dari satu arah sumber pembangkitan, sistem ini sangat rendah keandalannya karena apabila titik utama terganggu maka titik cabang akan terganggu[3]. Dilihat dari kondisi lokasi ada beberapa tiap titik beban yang tidak sama atau tidak imbang, penggunaan tiang untuk jaringan tegangan menengah dan tegangan rendah sudah sesuai dengan ketentuan yang ada maupun tiang pada penerangan, baik tiang yang terbuat dari bahan besi maupun dari bahan beton.

D. Penghantar Jaringan

Pada sistem jaringan distribusi tegangan rendah ini di Universitas Borneo Tarakan menggunakan kawat penghantar udara dan kawat penghantar tanah. Untuk kawat pilin udara berisolasi berjumlah empat kawat, dimana tiga kawat dipergunakan untuk tegangan tiga fasa sedang satu lagi kawat penghantaruntuk kawat nol dan jenis kawat pilin udara berisolasi yang digunakan adalah jenis NFA2X-T yaitu kawat pilin udara berpenghantar alumunium berisolasi XLPE dan ini sudah sesuai dengan PUIL 2000. Untuk kawat penghantar tanah berisolasi berselubung termoplastik dan pelindung perisai baja berjumlah empat kawat, dimana tiga kawat dipergunakan untuk tegangan tiga fasa sedangkan satu lagi kawat penghantar untuk kawat nol dan jenis kawat penghantar tanah yang digunakan adalah jenis NYY dan NYFGbY yaitu kabel tanah berpenghantar tembaga berisolasi dan berselubung PVC dengan kemampuan hantar arus terlampir dan ini sudah sesuai dengan PUIL 2000[4].

Jarak antara penghantar udara dengan tanah, jarak antar titiktumpu dan ketentuan saluran kabel tanah tegangan rendah sudah sesuai dengan PUIL 2000. Berdasarkan hasil pengamatan didapat bahwa beban tiap fasa pada gedung E2 tidak imbang yaitu : untuk fasa R 4.334 Watt, fasa S 8.646 Watt dan $\mathrm{T} 1.144$ Watt, demikian juga dengan beban pada gedung E10 yang tidak imbang yaitu: untuk fasa R 550 Watt, fasa S 880 Watt dan T 220 Watt, oleh karena itu besarnya penampang penghantar kabel tanah yang terpasang menggunakan kawat berpenghantar tembaga berisolasi termoplastik ada yang sesuai dan ada yang tidak sesuai dengan standart yang berlaku[5].Seharusnya standar Kemampuan Hantar Arus (KHA) penghantar kabel tanah berisolasi dan termoplastik yaitu:

1. Untuk kawat penghantar jenis NYY dengan besar penampang nominal 4x16 mm²0.6/1 KV dengan Kemampuan Hantar Arus (KHA) sebesar 89 A

2. Untuk kawat penghantar jenis NYY dengan besar penampang nominal $4 \times 2.5 \mathrm{~mm}^{2} \quad 0.6 / 1 \mathrm{KV}$ dengan Kemampuan Hantar Arus (KHA) sebesar 34 A.

Dengan jumlah beban yang terpasang di Universitas Borneo Tarakan, penghantar kabel tanah jenis NYY $4 \mathrm{x}$ $16 \mathrm{~mm}^{2}$ dari transformator distribusi menuju titik beban gedung tidak memenuhistandar yang berlaku. Penggunaan kawat penghantar udara berisolasi dipasang padadinding bangunan sudah sesuai dengan PUIL 2000 karena pada pasal7.16.8.1 menjelaskan "kabel udara yang dipasang pada dinding tembokbangunan harus berjarak tetap sekurang-kurangnya $5 \mathrm{~cm}$ terhadapbangunan itu".

Sambungan pada tiap penghantar cukup baik hal ini terlihat caramenyambung penghantar yaitu dengan cara menjepit, sehingga hubungan tersebut tidak akan mengendur atau menjadi terlalu panas dalam keadaankerja normal, dan untuk sambungan bersama penyambungan penghantar dilakukan dengan menjepit penghantar tanpa menyebabkan terpotongnya kawat penghantar. (PUIL 2000 hal :259) 
E. Sistem Pengamanan Distribusi

Pada jaringan distribusi tegangan rendah yang ada di Universitas Borneo Tarakan pengamanan untuk jaringan distribusi adalah dengan menggunakan arrester dan fuse cut out. Untuk pengamanan transformator sekunder dilayani oleh pemutus jaringan dan setiap gedung-gedung yang ada di UBT mempunyai pengaman Circuit Breaker sebagai pengaman arus lebih atau beban lebih.

F. Analisis Ketersediaan Daya

Analisis ketersedian daya sistem jaringan distribusi Universitas Borneo Tarakan adalah sebagai berikut :

Tabel 1. Data Hasil Perhitungan Transformator di Universitas Borneo tarakan

\begin{tabular}{llc}
\hline Komponen & $\lambda$ (Kegagalan/Tahun/Jam) & $\begin{array}{c}\boldsymbol{\mu} \\
\text { (Perbaikan/Tahun/Jam) }\end{array}$ \\
\hline TRAFO 1 & 0.00023 & 0.0028 \\
200 kVA & & 0 \\
\hline TRAFO 2 & 0 & 0 \\
1250 kVA & &
\end{tabular}

Catatan data sesuai dengan name plate transformator di Universitas Borneo Tarakan:

1) Ketersediaan pada transformator distribusi baik $100 \%$.

2) Kapasitas daya transformator $1200 \mathrm{kVA}$ adalah sebesar $105.000 \mathrm{kVA}$.

3) Kapasitas daya transformator $21250 \mathrm{kVA}$ adalah sebesar $721.600 \mathrm{kVA}$.

4) Untuk total jumlah keseluruhan kapasitas transformator yang terpasang di Universitas Borneo Tarakan sebesar 826.600 kVA.

5) Untuk jumlah keseluruhan beban daya berdasarkan hasil pengukuran di Universitas Borneo Tarakan sebesar $199.914 \mathrm{kVA}$.

Daya yang tersedia pada transformator distribusi Universitas Borneo Tarakan adalah $603.586 \mathrm{kVA}$ atau masih ada sekitar $39 \%$ daya yang tersedia pada transformator distribusi Universitas Borneo Tarakan.

Dari tabel 1. dapat dicari ketersediaan daya transformator 200 kVA Universitas Borneo Tarakan sebagai berikut:

$$
\begin{aligned}
& \mathrm{A}=\left(\frac{\mu}{\lambda+\mu}\right)_{0,0028} \\
& =\left(\frac{0,0028}{0,00023+0,0028}\right) \\
& =\frac{0,0028}{0,00303} \\
& =0,92409
\end{aligned}
$$

Dari tabel 1. dapat dicari ketersediaan daya transformator 1250 kVA Universitas Borneo Tarakan sebagai berikut:

$$
\begin{aligned}
\mathrm{A} & =\left(\frac{\mu}{\lambda+\mu p}\right) \\
& =\left(\frac{0}{0+0}\right) \\
& =\frac{0}{0} \\
& =1
\end{aligned}
$$

Tabel 2. Data Hasil Perhitungan CB Tiap Gedung di Universitas Borneo tarakan

\begin{tabular}{lcc}
\hline Komponen & $\begin{array}{c}\lambda \\
\text { (Kegagalan/Tahun } \\
\text { /Jam) }\end{array}$ & $\mu$ (Perbaikan/Tahun/Jam) \\
\hline $\begin{array}{l}\text { CB Rektor } \\
\text { Baru }\end{array}$ & 0 & 0 \\
\hline $\begin{array}{l}\text { CB Rektor } \\
\text { Lama }\end{array}$ & 0 & 0 \\
\hline
\end{tabular}

\begin{tabular}{lll}
\hline $\begin{array}{l}\text { CB Fakultas } \\
\text { Hukum }\end{array}$ & 0 & 0 \\
\hline $\begin{array}{l}\text { CB Fakultas } \\
\text { Ekonomi }\end{array}$ & 0 & 0 \\
\hline CB FKIP & 0 & 0 \\
\hline $\begin{array}{l}\text { CB Fakultas } \\
\text { Teknik }\end{array}$ & 0 & 0 \\
\hline $\begin{array}{l}\text { CB Fakultas } \\
\text { Perikanan }\end{array}$ & 0 & 0 \\
\hline $\begin{array}{l}\text { CB Fakultas } \\
\text { Pertanian }\end{array}$ & 0 & 0 \\
\hline CB Lab Sipil & 0 & 0 \\
\hline $\begin{array}{l}\text { CB } \\
\text { Rusunawa }\end{array}$ & 0 & 0 \\
\hline
\end{tabular}

Dari tabel 2. dapat dicari ketersediaan daya dari setiap CB sebagai berikut:

$$
\begin{aligned}
A & =\left(\frac{p}{x+a}\right) \\
& =\left(\frac{0}{0+0}\right) \\
& =\frac{0}{0} \\
& =1
\end{aligned}
$$

Dari tabel 3 dapat dicari ketersediaan daya dari setiap kabel sebagai berikut:

$$
\begin{aligned}
A & =\left(\frac{p}{x+p}\right) \\
& =\left(\frac{0}{0+0}\right) \\
& =\frac{0}{0} \\
& =1
\end{aligned}
$$

Dari tabel 4 dapat dicari ketersediaan daya dari setiap Bus sebagai berikut:

$$
\begin{aligned}
A & =\left(\frac{p}{2+a}\right) \\
& =\left(\frac{0}{0+0}\right) \\
& =\frac{0}{0} \\
& =1
\end{aligned}
$$

Tabel 3. Data hasil perhitungan kabel penghantar jaringan di Universitas Borneo Tarakan

\begin{tabular}{lcc}
\hline Komponen & $\begin{array}{c}\boldsymbol{\mu} \\
\text { (kegagalan/Tahun/Jam) }\end{array}$ & $\begin{array}{c}\boldsymbol{\mu} \\
\text { (Perbaikan/Tahun/Jam) }\end{array}$ \\
\hline Kabel 1 & 0 & 0 \\
\hline Kabel 2 & 0 & 0 \\
\hline Kabel 3 & 0 & 0 \\
\hline Kabel 4 & 0 & 0 \\
\hline Kabel 5 & 0 & 0 \\
\hline Kabel 6 & 0 & 0 \\
\hline Kabel 7 & 0 & 0 \\
\hline Kabel 8 & 0 & 0 \\
\hline Kabel 9 & 0 & 0 \\
\hline Kabel 10 & 0 &
\end{tabular}

Tabel 4 Data hasil perhitungan tiap Bus di Universitas Borneo Tarakan

\begin{tabular}{lcc}
\hline Komponen & $\begin{array}{c}\boldsymbol{\mu} \\
\text { (Kegagalan/Tahun/Jam) }\end{array}$ & $\begin{array}{c}\boldsymbol{\mu} \\
\text { (Perbaikan/Tahun/Jam) }\end{array}$ \\
\hline Bus 1 & 0 & 0 \\
\hline Bus 2 & 0 & 0 \\
\hline Bus 3 & 0 & 0 \\
\hline Bus 4 & 0 & 0 \\
\hline Bus 5 & 0 & 0 \\
\hline Bus 6 & 0 & 0 \\
\hline Bus 7 & 0 & 0 \\
\hline Bus 8 & 0 & \\
\hline
\end{tabular}




\begin{tabular}{lll}
\hline Bus 9 & 0 & 0 \\
\hline Bus 10 & 0 & 0 \\
\hline
\end{tabular}

Dari tabel 4.5 dapat dicari ketersediaan daya dari setiap titik beban sebagai berikut:

$$
\begin{aligned}
A & =\left(\frac{\mu}{\lambda+\mu}\right) \\
& =\left(\frac{0}{0+0}\right) \\
& =\frac{0}{0} \\
& =1
\end{aligned}
$$

\begin{tabular}{|c|c|c|}
\hline $\begin{array}{l}\text { Nama } \\
\text { Gedung }\end{array}$ & $\begin{array}{c}\lambda \\
\text { (Kegagalan/Tahun/Jam) }\end{array}$ & $\begin{array}{c}\boldsymbol{\mu} \\
\text { (Perbaikan/Tahun/Jam) }\end{array}$ \\
\hline $\begin{array}{l}\text { Gedung } \\
\text { RektoratBaru }\end{array}$ & 0 & 0 \\
\hline $\begin{array}{l}\text { Gedung F. } \\
\text { Hukum }\end{array}$ & 0 & 0 \\
\hline $\begin{array}{l}\text { Gedung F. } \\
\text { Ekonomi }\end{array}$ & 0 & 0 \\
\hline $\begin{array}{l}\text { GedungRekt } \\
\text { orat Lama }\end{array}$ & 0 & 0 \\
\hline $\begin{array}{l}\text { Gedung F. } \\
\text { FKIP }\end{array}$ & 0 & 0 \\
\hline $\begin{array}{l}\text { Gedung F. } \\
\text { Teknik }\end{array}$ & 0 & 0 \\
\hline $\begin{array}{l}\text { Gedung F. } \\
\text { Perikanan }\end{array}$ & 0 & 0 \\
\hline $\begin{array}{l}\text { Gedung F. } \\
\text { Pertanian }\end{array}$ & 0 & 0 \\
\hline $\begin{array}{l}\text { Gedung Lab } \\
\text { Sipil }\end{array}$ & 0 & 0 \\
\hline Rusunawa & 0 & 0 \\
\hline
\end{tabular}

Tabel 5. Data hasil perhitungan titik beban tiap gedung di Universitas Borneo Tarakan

G. Analisis Keandalan Sistem Jaringan Distribusi Eksponensial

1) Transformator $200 \mathrm{kVA}$

$$
\begin{aligned}
& \mathrm{t}=24 \times 30=720 \\
& \mathrm{t}=720 / 8760=0,082 \\
& \begin{aligned}
\mathrm{R}(\mathrm{t}) \quad & e^{-\lambda \mathrm{t}} \\
& =e^{-0,000221 \times 0,0822} \\
& =e^{-0,0001886} \\
& =0,99981
\end{aligned}
\end{aligned}
$$

2) Transformator $1250 \mathrm{kVA}$

$$
\begin{aligned}
\mathrm{R}(\mathrm{t}) & =e^{-\lambda t} \\
& =e^{-0.0} \\
& =e^{-0} \\
& =1
\end{aligned}
$$

3) Circuit Breaker

$$
\begin{aligned}
\mathrm{R}(\mathrm{t}) & =e^{-\lambda \mathrm{t}} \\
& =e^{-0.0} \\
& =e^{-0} \\
& =1
\end{aligned}
$$

4) Kabel Penghantar

$$
\begin{aligned}
\mathrm{R}(\mathrm{t}) & =e^{-\lambda \mathrm{t}} \\
& =e^{-0.0} \\
& =e^{-0} \\
& =1
\end{aligned}
$$

5) BUS

$$
\begin{aligned}
\mathrm{R}(\mathrm{t}) \quad & =e^{-\lambda \mathrm{t}} \\
& =e^{-0.00} \\
& =e^{-0} \\
& =1
\end{aligned}
$$

6) Titik Beban Gedung

$$
\begin{aligned}
\mathrm{R}(\mathrm{t}) & =e^{-\lambda \mathrm{t}} \\
& =e^{-0.0} \\
& =e^{-0} \\
& =1
\end{aligned}
$$

H. Analisis Indeks Keandalan SAIFI, SAIDI, CAIDI, ASAI dan ASUI

Analisis indeks keandalan sistem jaringan distribusi dengan perhitungaan manual dengan menggunakan rumus SAIFI, SAIDI, CAIDI, dan ASAI di Universitas Borneo Tarakan adalah sebagai berikut:

1) SAIFI (System Average Interruption Frequency Index)

$$
\begin{aligned}
\mathrm{SAIFI}= & \frac{\sum \mathrm{Xi}}{\sum \mathrm{Ni}} \\
& =\frac{2 \mathrm{f}_{\mathrm{f}} \mathrm{yr}}{10} \\
& =0,2 \mathrm{f} / \text { customer.yr }
\end{aligned}
$$

2) SAIDI (System Average Interruption Duration Index)

$$
\begin{aligned}
\text { SAIDI } & =\frac{\sum v_{i}}{\sum \mathrm{Ni}_{i}} \\
& =\frac{10 \mathrm{yr}}{10} \\
& =3 \mathrm{hr} / \text { customer.yr }
\end{aligned}
$$

3) CAIDI (Consumer Average Interruption Duration Index)

$$
\begin{aligned}
\text { CAIDI } & =\frac{\sum U i}{\sum \lambda i} \\
& =\frac{a h r / y x}{0,2 \mathrm{f} / \mathrm{yr}} \\
& =15 \mathrm{hr} / \text { customer interruption }
\end{aligned}
$$

4) ASAI (Average Service Availability Index)

$$
\begin{aligned}
\text { ASAI } & =\frac{\sum \text { Ni } x \text { Q760 }-\sum \text { Wi }}{\sum \text { Ni } x 8760} \\
& =\frac{10(8760)-20 \mathrm{hr} / \mathrm{yr}}{10(8760)} \\
& =0,9996 \mathrm{pu}
\end{aligned}
$$

5) ASUI (Average Service Unavailability Index)

$$
\begin{aligned}
\text { ASUI } & =\frac{\sum W_{i}}{\sum_{N i} x 9760} \\
& =\frac{30 \mathrm{hr} / \mathrm{yr}}{10(9760)} \\
& =0,00034 \mathrm{pu}
\end{aligned}
$$

Bahwa keandalan sistem jaringan distribusi tegangan rendah di Universitas Borneo Tarakan termasuk tipe yang rendah karena jaringan ini disuplai hanya dengan sebuah sistem distribusi tunggal (singlecircuit), apabila ada gangguan di saluran utama maka akan terganggu semua pada titik cabang saluran dan apabila ada perbaikan dititik cabang maka harus memutuskan saluran utamanya

\section{KESIMPULAN}

Berdasarkan hasil analisa data pada penelitian ini dapat diambil kesimpulan bahwa sistem jaringan distribusi tegangan rendah di Universitas Borneo Tarakan dengan urutan sebagai berikut:

a. Transformator distribusi sudah dapat menyuplai semua beban yang ada di lingkungan Universitas Borneo Tarakan dengan daya $1250 \mathrm{kVA}$ yaitu pada gedung Fakultas Hukum, Fakultas Ekonomi, gedung Rektorat Lama, Fakultas Keguruan dan Ilmu Pendidikan, Fakultas Teknik, Fakultas Perikanan dan 
Ilmu Kelautan, Fakultas Pertanian, LAB Fakultas Teknik Sipil, dan Rusunawa.

b. Transformator distribusi sudah dapat menyuplai beban yang ada di gedung Rektorat Baru Universitas Borneo Tarakan dengan daya $200 \mathrm{kVA}$.

c. Jumlah beban keseluruhan di Universitas Borneo Tarakan untuk perhitungan tiap fasa adalah sebagai berikut:

1) Untuk fasa R, beban terhitung adalah sebesar : 67.408 Watt

2) Untuk fasa $S$, beban terhitung adalah sebesar : 77.616 Watt

3) Untuk fasa $T$, beban terhitung adalah sebesar : 54.890 Watt

Sehingga jumlah beban keseluruhan menjadi 199.914 Watt

d. Pengamanan jaringan distribusi tegangan rendah di Universitas Borneo Tarakan menggunakan Arrester, sedangkan untuk melindungi terhadap arus lebih adalah Fuse Cut out. Nilai ketersediaan daya dan keandalan transformator $200 \mathrm{kVA}$ sistem jaringan distribusi di Universitas Borneo Tarakan terhitung sebesar 0,92409 dan 0,99981.

e. indekskeandalan sistem jaringan distribusi di Universitas Borneo Tarakan dengan menggunakan perhitungan SAIFI, SAIDI, CAIDI, ASAI dan ASUI adalah:

1) SAIFI :0,2 kegagalan/tahun konsumen

2) SAIDI : 3 jam/tahun konsumen

3) CAIDI : 15jam/gangguan konsumen

4) ASAI :0,9996 perunit

5) ASUI : 0,00034 perunit

Ketersediaan daya dan keandalan sistem jaringan distribusi di Universitas Borneo Tarakan untuk keseluruhannya dapat dikatakan handal, karena dapat dilihat melalui data-data hasil pengamatan langsung dilapangan dan menggunakan rumus yang dipakai untuk mengetahui ketersediaan daya dan keandalannya. untuk kegagalannya sendiri hanya 2 kali kegagalan selama 1 tahun beroperasi yaitu hanya Transformator $200 \mathrm{kVA}$ yang menyuplai ke Gedung Rektorat Baru.

\section{REFERENSI}

[1] Adi, Suryawan wibowo. 2007. Analisis Ketersediaan Daya dan Keandalan Sistem Jaringan Distribusi di Fakultas Teknik Universitas Negeri Semarang.Fakultas Teknik, Universitas Negeri Semarang.

[2] Kadir, Abdul 2000. Distribusi Dan Utilisasi Tenaga Listrik. Jakarta : Penerbit Universitas Indonesia (UIPress).

[3] Priyanta,Dwi. Ir., MSE, Modul Ajar Keandalan Dan Perawatan, Institut Teknologi Sepuluh November, Surabaya, 2000.

[4] Adi Soeprijanto, Fauziah, dan Ontoseno Penangsang, 2012. Studi Perbaikan Keandalan Jaringan Distribusi Primer Dengan Pemasangan Gardu Induk Sisipan Di Kabupaten Enrekang Sulawesi Selatan. Jurnal Teknik Elektro. ISSN: 2301-9271. Vol.1. Hal.119-124.

[5] Aditya Teguh Prabowo, Bambang Winardi, dan Susatyo Handoko, 2013. Analisis Keandalan Sistem
Distribusi 20 kV Pada Penyulang Pekalongan 8 Dan 11. Jurnal Teknik Elektro. ISSN: 2302-9927, 1005. Vol. 2, No.4.

[6] Arifani Indah Nur, dan Heru Winarno, 2013. Analisis Nilai Indeks Keandalan Sistem Jaringan Distribusi Udara $20 \mathrm{kV}$ Pada Penyulang Pandean Lamper 1,5,8,9,10 Di GI Pandean Lamper. Jurnal Teknik Elektro. Vol.17 